\title{
Diagnostic and economic evaluation of new biomarkers for Alzheimer's disease: the research protocol of a prospective cohort study
}

Ron LH Handels ${ }^{1}$, Pauline Aalten ${ }^{1}$, Claire AG Wolfs ${ }^{1}$, Marcel OldeRikkert ${ }^{2}$, Philip Scheltens ${ }^{3}$, Pieter Jelle Visser ${ }^{1,3}$, Manuela A Joore ${ }^{4}$, Johan L Severens ${ }^{4,5}$ and Frans RJ Verhey ${ }^{1,6^{*}}$

\begin{abstract}
Background: New research criteria for the diagnosis of Alzheimer's disease (AD) have recently been developed to enable an early diagnosis of AD pathophysiology by relying on emerging biomarkers. To enable efficient allocation of health care resources, evidence is needed to support decision makers on the adoption of emerging biomarkers in clinical practice. The research goals are to 1) assess the diagnostic test accuracy of current clinical diagnostic work-up and emerging biomarkers in MRI, PET and CSF, 2) perform a cost-consequence analysis and 3) assess long-term cost-effectiveness by an economic model.
\end{abstract}

Methods/design: In a cohort design 241 consecutive patients suspected of having a primary neurodegenerative disease are approached in four academic memory clinics and followed for two years. Clinical data and data on quality of life, costs and emerging biomarkers are gathered.

Diagnostic test accuracy is determined by relating the clinical practice and new research criteria diagnoses to a reference diagnosis. The clinical practice diagnosis at baseline is reflected by a consensus procedure among experts using clinical information only (no biomarkers). The diagnosis based on the new research criteria is reflected by decision rules that combine clinical and biomarker information. The reference diagnosis is determined by a consensus procedure among experts based on clinical information on the course of symptoms over a two-year time period.

A decision analytic model is built combining available evidence from different resources among which (accuracy) results from the study, literature and expert opinion to assess long-term cost-effectiveness of the emerging biomarkers.

Discussion: Several other multi-centre trials study the relative value of new biomarkers for early evaluation of AD and related disorders. The uniqueness of this study is the assessment of resource utilization and quality of life to enable an economic evaluation. The study results are generalizable to a population of patients who are referred to a memory clinic due to their memory problems.

Trial registration: NCT01450891

\footnotetext{
*Correspondence: f.verhey@maastrichtuniversity.nl

'Alzheimer Centre Limburg, School for Mental Health and Neuroscience

(MHeNS), University Medical Centre, P.O. Box 5800, 6202, AZ Maastricht, the Netherlands

${ }^{6}$ Department of Psychiatry and Neuropsychology, University Hospital of

Maastricht/Alzheimer Centre Limburg, P.O. Box 5800, 6202, AZ Maastricht,

The Netherlands

Full list of author information is available at the end of the article
} 


\section{Background}

Alzheimer's disease (AD) and other dementing disorders are common in the elderly, with a worldwide prevalence estimated in 2010 at 35.6 million, which will double every 20 years to 115.4 million in 2050 . AD has a substantial impact on the person who suffers from the disease, his or her family and society [1]. AD affects a person's cognition, behavior and functional ability, and it is one of the leading causes of disability in older people living in developed countries [2].

The NINCDS-ADRDA criteria [3] are currently applied in diagnostic guidelines $[4,5]$ to determine $\mathrm{AD}$ aetiology. Scientific knowledge, advanced imaging techniques and cerebrospinal fluid analyses have evolved since the publication of these criteria in 1984. This has led to much debate and the proposition of new clinical and research criteria to enhance diagnostic accuracy, even at the stage of early clinical symptoms [6-10]. These criteria distinguish between the AD pathophysiological process and the clinically observable syndrome to enable determination of $\mathrm{AD}$ in a pre-dementia state; e.g. mild cognitive impairment (MCI). In the end the criteria are meant to support therapy decision making (when effective treatments are available) or to determine the likelihood of cognitive and functional progression to a more severe disease state. Emerging biomarkers are attributed a more prominent role in the diagnostic criteria; amyloid $\beta 42$, total tau and phosphorylated-tau in the cerebrospinal fluid (CSF), amyloid tracer uptake and fluorodeoxyglucose (FDG) in positron emission tomography (PET), hippocampal volume and medial temporal atrophy in structural magnetic resonance imaging (MRI) and single photon emission tomography (SPECT) perfusion imaging. However, validation of the criteria is needed before adoption of the proposed role of new biomarkers in clinical practice [9].

The ultimate goal of diagnostic testing is to guide disease management in order to improve patient outcomes and patient well-being. Tests that lack this potential should be regarded obsolete [11,12]. This has raised an urgent need for health technology assessment to address the direct, intended consequences of technologies as well as the indirect, unintended consequences for the evaluation of the value of diagnostic strategies including biomarker for $\mathrm{AD}$ compared to current clinical practice. Evidence is needed to support decision makers on the adoption of new diagnostic tests in clinical practice to enable efficient allocation of health care resources.

\section{Study aim}

The general aim of the study is to assess the clinical and economic value of current, emerging and novel (to be developed) techniques for an early diagnosis of $\mathrm{AD}$ and related disorders. In this paper the methodology is described.

The research goals are:

1. To assess the diagnostic test accuracy of the current clinical standard diagnostic work-up and emerging diagnostic biomarkers in MRI, PET and CSF

2. To assess costs and effects for the follow-up period to perform a cost-consequence and cost-effectiveness analysis

3. To develop a preliminary economic model to assess the uncertainty surrounding long-term cost-effectiveness of diagnostic strategies

\section{Methods/design}

\section{Study design}

A cohort design was chosen because an assessment of test combinations within a randomized controlled trial would require the evaluation of many diagnostic strategies for which the number of subjects needed would exponentially increase [13]. To determine the diagnostic value of emerging biomarkers for $\mathrm{AD}$ and related disorders both a clinical diagnosis and diagnosis based on emerging biomarkers (index tests) are compared with a reference diagnosis. Due to limited ability of biopsy (which is unethical) or autopsy (which requires follow up until death) a two-year follow up of the clinical course is used as a proxy to obtain information on the state of the disease at baseline; so-called delayed-type cross-sectional accuracy study design [12]. Four academic memory clinics (Leiden University Medical Centre, Maastricht University Medical Centre, Radboud University Nijmegen Medical Centre and VU University Medical Centre) specialized in the diagnosis and treatment of memory disorders participate in the study. Two memory clinics are settled within a department of geriatrics, one within neurology and one within psychiatry. The study is performed within the framework of CTMM, the Center for Translational Molecular Medicine (www.ctmm.nl), a Dutch public-private partnership; project LeARN (grant $02 \mathrm{~N}-101$ ).

\section{Subjects}

For the study, 241 consecutive patients of the participating memory clinics who were suspected of having a primary neurodegenerative disease were included for participating in the study from October 2009 to May 2011; this included all patients with subjective and/or objective memory complaints. Eligibility criteria were chosen to represent the current clinical situation and enable generalisability to clinical practice (see Table 1). Informed consent was obtained from both the patient and the informal caregiver. Gender, age and reason for refusal were obtained for patients unwilling to participate. 


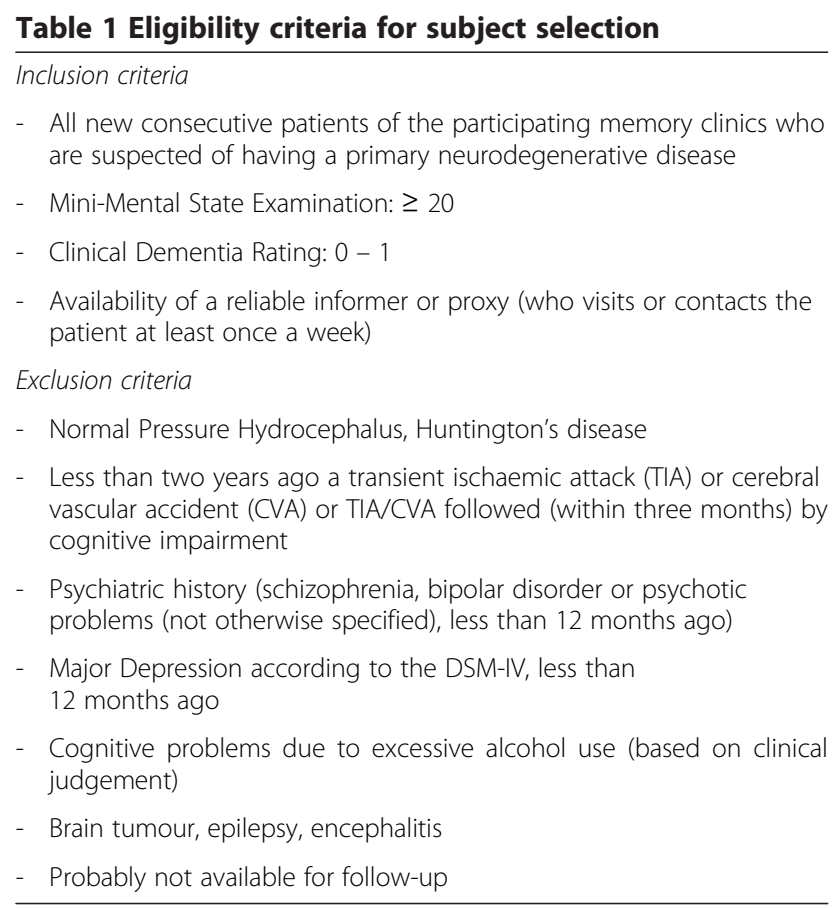

\section{Data assessment}

Each centre collects a minimum dataset of clinical information based upon the dataset protocol used for The String of Pearls Initiative - Pearl Neurodegenerative Diseases (www.string-of-pearls.org), cost data and data on emerging biomarkers. Table 2 provides an overview of all patient and informal caregiver assessments. Assessments take place at baseline and at 12 and 24 months follow up during a visit (from both patient and informal caregiver) to the memory clinic. Furthermore, several questionnaires were composed in a booklet to measure resource consumption and quality of life. This is filled out by the informal caregiver at baseline, 3, 12 and 24 months.

\section{Clinical data}

Demographic and medical information is retrieved from an open interview with both patient and informal caregiver and physical examination by a clinician.

The Mini Mental State Examination is used to detect cognitive impairment, to assess its severity and to monitor cognitive changes over time [14]. The Clinical Dementia Rating scale (CDR) [15,16] provides a global rating of dementia severity. The Geriatric Depression Scale-15 [17] is applied to detect depression. Patient's behavioural and psychological problems are measured by the Neuropsychiatric Inventory (NPI) [18]. The Disability assessment for Dementia (DAD) is assessed to evaluate basic and instrumental activities in daily activities [19]. The information of both the NPI and DAD is obtained from a caregiver familiar with the patient's behaviour by means of a semi structured interview. Caregiver's burden of care is assessed using the disease specific Sense of Competence Questionnaire (SoCQ) [20,21].

Neuroimaging markers include medial temporal lobe atrophy measurements and white matter lesions which are qualitatively scored based on 3 T MRI scan images.

Neuropsychological examination consists of a standardized battery of cognitive tests performed by a (neuro) psychologist. Tests include Rey's Verbal Learning Test [22,23], Visual Association Test [24], and Digit-Span [25] to assess memory; Letter Digit Substitution Test [26] to assess mental processing rate; and Stroop ColorWord Test [27] and Trail Making Test [28,29] to assess attention, concentration and interference. Raw scores were converted to z-scores, adjusting for age, education and gender.

\section{Quality of life data}

Patient's generic quality of life is measured by the EQ$5 \mathrm{D}$ instrument. It was developed and validated in a number of European countries including the Netherlands [30-32] and it has been validated in patients with dementia [33,34]. The EQ-5D describes health status according to five three-level dimensions, which yields 243 potential combinations of health states. Each combination leads to a utility score by means of an additive function derived from the UK general population [35,36].

Patient disease specific quality of life is measured by the validated Quality of Life - Alzheimer's Disease scale (QoL-AD) $[37,38]$. It has 13 items covering the domains of physical health, energy, mood, living situation, memory, family, marriage, friends, self as a whole, ability to do chores around the house, ability to do things for fun, money, and life as a whole. Scale scores range from 13 to 52 with higher scores indicating greater QoL. An improvement of 3 points on the QoL-AD is judged as clinically relevant as this indicates a change of well-being on one of the domains from very poor to excellent [39].

Patient EQ-5D is assessed by the patient during the visit to the memory clinic. Furthermore, the informal caregiver judges the EQ-5D and QoL-AD for the situation of the patient and for his/her own situation and fills this out in the booklet of questionnaires.

Care-related quality of life of informal caregivers is assessed by the CarerQol[40]. It combines seven important burden dimensions with a valuation component (a visual analogue scale (VAS)) for happiness. The seven burden dimensions are 1) fulfilment; 2) relational problems; 3) mental problems; 4) problems with daily activities; 5) financial problems; 6) support; and 7) physical problems. The CarerQol-VAS ranges from 0 ("completely unhappy") to 100 ("completely happy") 
Table 2 Overview of patient and informal caregiver assessments at baseline and follow-up

\begin{tabular}{|c|c|c|c|c|c|}
\hline Outcome measure & Operationalization/type of instrument & B & T3 & $\mathrm{T} 12$ & $\mathrm{~T} 24$ \\
\hline \multicolumn{6}{|l|}{ Clinical data } \\
\hline Demographic data & History taking & $P$ & & $P$ & $\mathrm{P}$ \\
\hline Cognitive impairment & Mini-mental State Examination & $P$ & & P & P \\
\hline Dementia severity & Clinical Dementia Rating & $P$ & & $P$ & $\mathrm{P}$ \\
\hline Functional disability & Disability Assessment for Dementia & $P$ & & $P$ & $P$ \\
\hline Neurological and physical examination & $\begin{array}{l}\text { Neurological assessment and evaluation } \\
\text { of co-morbidities }\end{array}$ & $\mathrm{P}$ & & $P$ & P \\
\hline Neuropsychiatric problems & Neuropsychiatric Inventory & $\mathrm{P}$ & & $P$ & P \\
\hline Depression & Geriatric Depression Scale 15 & $\mathrm{P}$ & & $P$ & $P$ \\
\hline Cerebral atrophy and white matter lesions & $\begin{array}{l}\text { Structural MRI (T1-weighted, T2-weighted } \\
\text { and FLAIR) }\end{array}$ & $P$ & & & \\
\hline Neuropsychological Assessment & $\begin{array}{l}\text { Rey's Verbal Learning Test, Visual } \\
\text { Association Test, Digit-Span, } \\
\text { Letter Digit Substitution Test, } \\
\text { Stroop Color-Word Test, Trail Making Test }\end{array}$ & $P$ & & $P$ & $P$ \\
\hline \multicolumn{6}{|l|}{ Quality of life data } \\
\hline Patient generic quality of life & EQ-5D & $I^{*} / \mathrm{P}$ & $1^{*}$ & I*/P & $I^{*} / \mathrm{P}$ \\
\hline Patient disease specific quality of life* & QoL-AD & $I^{*}$ & $I^{*}$ & ।* & $I^{*}$ \\
\hline Caregiver generic quality of life ${ }^{*}$ & $E Q-5 D$ & 1 & 1 & I & । \\
\hline Caregiver disease specific quality of life* & QoL-AD & I & I & । & । \\
\hline Caregiver burden* & Sense Of Competence & 1 & 1 & 1 & । \\
\hline Care-related quality of life* & Carer Quality of Life & 1 & 1 & I & I \\
\hline \multicolumn{6}{|l|}{ Cost data* } \\
\hline Resource utilization and caregiver time & RUD-Lite & I & 1 & I & । \\
\hline Work productivity and absence & Productivity and Disease Questionnaire & 1 & I & I & I \\
\hline $\begin{array}{l}\text { Consequences of informal caregiving } \\
\text { on paid or unpaid work }\end{array}$ & Health and Labour Questionnaire & I & I & 1 & I \\
\hline Other resource use & & 1 & I & 1 & I \\
\hline \multicolumn{6}{|l|}{ Emerging biomarker data } \\
\hline Functional connectivity & Resting state functional MRI & $P$ & & & \\
\hline White matter integrity & Diffusion tensor imaging & $P$ & & & \\
\hline Hippocampal volume & Structural MRI & $P$ & & & \\
\hline Glucose metabolism & Fluorodeoxyglucose PET† & $P$ & & & \\
\hline Amyloid plaque deposition & Pittsburgh compound B PET+, CSF A $1-42$ & $P$ & & & \\
\hline Tau & CSF total tau, CSF phosphorylated tau & $P$ & & & \\
\hline
\end{tabular}

*These items were assessed by the informal caregiver by means of a booklet in which several questionnaires were composed for resource consumption and quality of life.

tData on this item are only collected at the memory clinic of the VU University Medical Centre Amsterdam.

Abbreviations: B, Baseline; FLAIR, Fluid attenuation inversion recovery; I, Information retrieved from informal caregiver; MRI, Magnetic Resonance Imaging;

$\mathrm{P}$, Information retrieved from patient; PET, positron emission tomography; QoL-AD, Quality of Life Alzheimer's Disease scale; RUD-Lite, Resource Utilization

In Dementia; T3, 3 month follow-up measurement; T12, 12 month follow-up measurement; T24, 24 month follow-up measurement.

and has been validated in a Dutch sample of heterogeneous caregivers.

\section{Cost data}

Cost data are retrieved by the composed booklet of questionnaires. Patient resource utilization and caregiver time, which often contains productivity losses, are assessed by means of the short version of the Resource
Utilization in Dementia-questionnaire (RUD-lite). This instrument has been validated and proved to register over $95 \%$ of the costs involved in $\mathrm{AD}$-care [41]. Work status, income, and productivity losses of both the patient and caregiver are assessed by the adjusted PRODISQ (PROductivity and DISease Questionnaire) [42]. The consequences of informal caregiving on paid or unpaid work are assessed by the Health and Labour 
Questionnaire on a two-week scale on which is indicated whether one was ill, ill by caregiving or not ill [43]. Additional questions are asked referring to the number of visits to various health care professionals, resources or aids that are bought and other out-of-pocket costs.

\section{Emerging biomarker data}

Biomarkers can be divided into two categories, one reflecting the presence of beta-amyloid protein $(A \beta)$ and one reflecting neuronal degeneration or injury. A pathological cascade is hypothesized in which basically $A \beta$ markers become abnormal first, followed by neuronal injury $[9,44]$.

The biomarkers included in this project are outlined in Table 3. CSF is collected and Amyloid $\beta 42$, total tau and phosphorylated-tau are analyzed using a standardized quantitative method. FDG uptake and Pittsburgh compound $\mathrm{B}$ binding $(\mathrm{PiB})$ on PET are both qualitatively rated by a radiologist and quantitatively analyzed by standardized methods. Whole brain and hippocampal volume, white matter integrity and functional connectivity derived by MR imaging are quantitatively analyzed by a researcher. These tests are not part of the current routine clinical diagnostic procedure. They are judged and analyzed independently and blindly. The outcome of each test is dichotomous or continuous, both for $\mathrm{AD}$ aetiology and progression of cognitive decline.

\section{Baseline clinical diagnosis and reference diagnosis}

Current clinical practice diagnosis is reflected by a consensus procedure among experts using baseline clinical information only, excluding any information of emerging biomarkers to prevent underestimating their accuracy.

The reference diagnosis is also determined by a consensus procedure among experts based on clinical information on the course of symptoms over a two-year time period and applying the core clinical criteria for the diagnosis of dementia due to $\mathrm{AD}$ [8] and core clinical

Table 3 Included biomarkers in the project categorized by reflecting $A \beta$ or neuronal injury

\begin{tabular}{lll}
\hline Technique & $\mathbf{A} \boldsymbol{\beta}$ accumulation & Neuronal dysfunction \\
\hline CSF & Amyloid $\beta 42$ in the CSF & $\begin{array}{l}\text { total tau and phosphorylated-tau } \\
\text { in CSF }\end{array}$ \\
PET & $\begin{array}{l}\text { amyloid tracer uptake } \\
\text { in PET }\end{array}$ & $\begin{array}{l}\text { fluorodeoxyglucose PET } \\
\text { MRI }\end{array}$ \\
& White matter integrity (DTI) \\
& Functional connectivity (rsfMRI) \\
& Whole brain volume \\
& Hippocampal volume
\end{tabular}

Abbreviations: $A \beta$, beta-amyloid protein; $C S F$, cerebrospinal fluid; DTI, diffusion tensor imaging; MRI, magnetic resonance imaging; PET, positron emission tomography; rsfMRl, resting state functional magnetic resonance imaging. criteria for the diagnosis of MCI due to AD [7]. Experts are kept blind for any information of the emerging markers under evaluation. Evaluating all cases by expert panel discussion meetings is highly time consuming. Therefore, first expert raters will assess all cases by means of an internet based form and if consensus is not reached the case will be discussed by a panel discussion meeting. The consensus diagnosis during the expert panel meetings is based on a modified Delphi method in which face-to-face discussions are held $[45,46]$.

\section{Analyses}

Several diagnostic procedures based on current practice and emerging biomarker information (index tests) are compared to the reference diagnosis. First, AD aetiology based on the core clinical criteria $[7,8]$ is evaluated. This is reflected by the baseline diagnosis as determined by the consensus procedure. No information of any emerging biomarker is included. Second, AD aetiology based on the research criteria as established by the National institute on aging and the Alzheimer's Association are evaluated [9]. At last, several explorative decision rules are applied including clinical information and biomarker information to determine $\mathrm{AD}$ aetiology and suspected progression of cognitive decline within two years.

\section{Research goal 1: Diagnostic test accuracy}

Diagnostic test accuracy is determined by relating index test results to the reference diagnosis (reference test). All diagnoses consist of a dichotomous outcome value on underlying pathology of the clinical syndrome and on (expected) progression of cognitive decline within two years. Separately for aetiology and progression of cognitive decline each index test result for each case is indicated as either true positive, true negative, false positive or false negative based on the reference diagnosis (reference test). This enables the calculation of accuracy estimates: sensitivity, specificity, positive predictive value, negative predictive value, likelihood ratio and (an increase of) the Area Under the Curve of a Receiver Operating Characteristic curve.

Finally, novel innovative diagnostic tests are developed during the course of this study by other cooperating researchers for which proof of principle does not yet exist. These tests will be evaluated as soon as evaluation in clinical subjects is possible. To assess diagnostic accuracy the tests will be applied in subgroups of the cohort retrospectively (for CSF samples) or using a case-control design.

\section{Research goal 2: Cost-consequence and cost-effectiveness analysis}

A cost-consequence analysis is performed listing all relevant costs and effects without aggregating it into a ratio 
[47] allowing decision-makers to choose the outcome of particular interest to include in an economic analysis. Average costs and consequences of the whole cohort are compared with the subgroup of patients who have received a correct diagnosis according to the reference test. This enables the comparison of the current diagnostic practice costs and effects and the costs and effects of an ideal situation (a costless diagnostic test with 100\% accuracy). The difference indicates the maximum possible achievable benefit of new biomarkers for $\mathrm{AD}$ and related disorders in terms of costs and health effects. Furthermore, a cost-effectiveness analysis is performed comparing current practice with diagnostic procedures that include emerging biomarkers. The change in costs is compared to the change in diagnostic accuracy to obtain a cost-effectiveness ratio in terms of costs per correctly diagnosed patient.

\section{Research goal 3: Decision analytic model}

Finally a decision analytic model is built which provides a framework combining available evidence from different resources among which (accuracy) results from the study, literature and expert opinion. A decision analytic model can be defined as a set of mathematical relationships that form a structure reflecting the natural progression of a disease. By simulating patients or fractions of a population, these models enable the estimation of the likelihood of each consequence and its corresponding costs and effects [48]. It is applied to evaluate the shortterm cost-effectiveness in terms of cost per correct diagnosis and long-term cost-utility in terms of cost per quality adjusted life year gained of diagnostic strategies under evaluation. Utility scores will be used to calculate Quality Adjusted Life Years (QALY). Patients who pass away during the year covered by the evaluation will be given a utility score of zero from the exact time of death. QALYs will be derived using the trapezium rule. A societal viewpoint will be adopted including the evaluation of all relevant costs and effects to calculate the societal benefits.

The cohort design facilitates the evaluation of many different diagnostic procedures by varying the place of a new diagnostic marker in the clinical pathway. Each procedure generates specific proportions of correct or incorrect diagnoses. Average costs and effects of correct and incorrect diagnoses are applied to calculate the total costs and effects of each procedure.

Sensitivity analysis will be performed taking into account both first order uncertainty regarding variation between patients in a homogeneous group and second order uncertainty regarding the true value of the parameters included in the model. This also enables the evaluation of an earlier diagnosis, different test sequences and the effect of possible new disease modifying drug treatments.

\section{Sample size and missing data}

A telephone interview is performed for patients who refuse follow-up assessments to determine the reason for refusal, possible cognitive decline and interference with daily activities, and to assess the CDR. Incomplete data will be imputed by means of a regression model. Complete missing data or data missing covariates will be imputed using Rubin's multiple imputation (MI) procedure.

Sample size is based on an $80 \%$ accuracy of current clinical practice to determine correct aetiology [4] and $70 \%$ in non-demented patients [49]. Applying a type I error $(\alpha=5 \%)$, type II error $(\beta=80 \%)$, drop-out rate of $10 \%$ and minimum clinically relevant difference of $10 \%$ accuracy increase requires 219 patients to be included in the study.

Contrary to clinical studies, economic evaluations are not based on testing hypotheses. Their goal is to assess decision uncertainty. Therefore, economic evaluations are restricted to the estimation of the uncertainty surrounding cost-effectiveness (expressed in a statistical confidence interval). Within this Bayesian framework, classical inference (and therewith a power analysis) is irrelevant [50].

\section{Ethical considerations}

According to the medical ethics committee "MedischEthischeCommissieazM/UM" the research protocol complies with the Declaration of Helsinki (October 2008, www.wma.net, ref.nr.: MEC 09-3-038) and with the Medical Research Involving Human Subjects Act and codes on 'good use' of clinical data and biological samples as developed by the Dutch Federation of Medical Scientific Societies.

\section{Discussion}

This research protocol describes the methods used to assess the clinical and economic value of new diagnostic approaches for the diagnosis of $\mathrm{AD}$. A delayed-type cross-sectional accuracy study design is chosen because a randomized clinical trial comes with ethical issues, long follow-up time and limited power. Two hundred forty one consecutive patients suspected of having a primary neurodegenerative disease are followed up for two years and a reference diagnosis is determined by an independent consensus expert panel. Eligibility criteria are chosen to maximally reflect a patient cohort within clinical practice.

Several other multi-centre trials study the relative value of new biomarkers for early evaluation of $\mathrm{AD}$ and related disorders. The Alzheimer's Disease Neuroimaging Initiative (ADNI) in North America is aimed to identify neuroimaging measures and biomarkers associated with cognitive and functional changes in healthy elderly subjects and in subjects who have MCI and AD 
[51]. Furthermore, the 'Development of Screening Guidelines and Clinical Criteria for Predementia AD' (DESCRIPA) study is aimed to develop screening guidelines for predementia $\mathrm{AD}$ in the general population [52]. Both include markers in PET, MR imaging and CSF. The uniqueness of this study is the assessment of resource utilization and quality of life to enable an economic evaluation. Furthermore, the decision analytic model enables the evaluation of the optimal diagnostic strategy and the evaluation of diagnostic techniques to be developed during the study in sub-cohorts of the study population. At last, without a disease modifying treatment, the added value of biomarkers is uncertain. Therefore, the availability of such treatment is explored in the sensitivity analysis.

The study has some limitations. It focuses on applying new tests for diagnostic or prognostic goals. Screening and treatment monitoring are outside the scope of this study. A follow-up period of two years was taken as a compromise to maximise the time for the disease to express symptoms of progression (to prevent false negative reference diagnoses) and to minimize the time to prevent the start of a new disease episode after the baseline assessment (to prevent false positive reference diagnosis). It may take up to 10 years before all symptoms of dementia come to expression in subjects with $\mathrm{AD}$ pathology [53].

The study results are generalizable to a population of patients who are referred to a memory clinic of a university medical centre due to their memory problems.

\section{Competing interests}

The author(s) declare that they have no competing interests.

\section{Authors' contributions}

$\mathrm{CW}$ designed the study and assisted $\mathrm{RH}$ in drafting the manuscript. FV (project leader) designed the study. JS (project leader) designed the study. MOR designed the study. PA (project coordinator) designed the study. PJV designed the study. PS designed the study. $\mathrm{RH}$ designed the study and drafted the manuscript. All authors read and approved the final manuscript.

\section{Acknowledgements}

This research is performed within the framework of CTMM, the Center for Translational Molecular Medicine (www.ctmm.nl), project LeARN (grant $02 \mathrm{~N}$ 101). All authors' source of funding is the framework of CTMM, grant $02 \mathrm{~N}$ 101. The funding body had no role in the study design, collection, analysis or interpretation of data, and in writing of the manuscript. The funding body checked the manuscript for possible intellectual property and approved the manuscript for publication without suggested revisions. The source of funding for the manuscript preparation is the framework of CTMM, grant 02 $\mathrm{N}-101$.

\section{Author details}

${ }^{1}$ Alzheimer Centre Limburg, School for Mental Health and Neuroscience (MHeNS), University Medical Centre, P.O. Box 5800, 6202, AZ Maastricht, the Netherlands. ${ }^{2}$ Alzheimer Centre Nijmegen, Radboud University Nijmegen Medical Centre, Nijmegen, the Netherlands. ${ }^{3}$ Alzheimer Centre, Department of Neurology, VU University Medical Centre, Amsterdam, the Netherlands. ${ }^{4}$ Maastricht University, CAPHRI School for Public Health and Primary Care, Faculty of Health Medicine and Life Sciences, Department of Health Organization, Policy and Economics, P.O. Box 616, 6200, MD Maastricht, the Netherlands. ${ }^{5}$ Institute of Health Policy and Management,
Erasmus University Rotterdam, P.O. Box 1738, 3000, DR Rotterdam, The Netherlands. ${ }^{6}$ Department of Psychiatry and Neuropsychology, University Hospital of Maastricht/Alzheimer Centre Limburg, P.O. Box 5800, 6202, AZ Maastricht, The Netherlands.

Received: 1 November 2011 Accepted: 31 July 2012

Published: 10 August 2012

\section{References}

1. Prince M, Jackson J: World Alzheimer Report. 2009. http://www.alz.co.uk/ research/worldreport/.

2. Wimo A, Winblad B, Jonsson L: The worldwide societal costs of dementia: Estimates for 2009. Alzheimers Dement 2010, 6(2):98-103.

3. McKhann G, Drachman D, Folstein M, Katzman R, Price D, Stadlan EM: Clinical diagnosis of Alzheimer's disease: report of the NINCDS-ADRDA Work Group under the auspices of Department of Health and Human Services Task Force on Alzheimer's Disease. Neurology 1984, 34(7):939-944

4. Knopman DS, DeKosky ST, Cummings JL, Chui H, Corey-Bloom J, Relkin N, Small GW, Miller B, Stevens JC: Practice parameter: diagnosis of dementia (an evidence-based review), Report of the Quality Standards Subcommittee of the American Academy of Neurology. Neurology 2001, 56(9):1143-1153.

5. Waldemar G, Dubois B, Emre M, Georges J, McKeith IG, Rossor M, Scheltens P, Tariska P, Winblad B: Recommendations for the diagnosis and management of Alzheimer's disease and other disorders associated with dementia: EFNS guideline. Eur J Neurol 2007, 14(1):e1-e26.

6. Dubois B, Feldman HH, Jacova C, Cummings JL, Dekosky ST, BarbergerGateau P, Delacourte A, Frisoni G, Fox NC, Galasko D, et al: Revising the definition of Alzheimer's disease: a new lexicon. Lancet Neurol 2010, 9(11):1118-1127.

7. Albert MS, Dekosky ST, Dickson D, Dubois B, Feldman HH, Fox NC, Gamst A, Holtzman DM, Jagust WJ, Petersen RC, et al: The diagnosis of mild cognitive impairment due to Alzheimer's disease: Recommendations from the National Institute on Aging-Alzheimer's Association workgroups on diagnostic guidelines for Alzheimer's disease. Alzheimers Dement 2011, 7(3):270-279.

8. McKhann GM, Knopman DS, Chertkow H, Hyman BT, Jack CR Jr, Kawas CH, Klunk WE, Koroshetz WJ, Manly JJ, Mayeux R, et al: The diagnosis of dementia due to Alzheimer's disease: Recommendations from the National Institute on Aging-Alzheimer's Association workgroups on diagnostic guidelines for Alzheimer's disease. Alzheimers Dement 2011, 7(3):263-269.

9. Jack CR Jr, Albert MS, Knopman DS, McKhann GM, Sperling RA, Carrillo MC, Thies B, Phelps $\mathrm{CH}$ : Introduction to the recommendations from the National Institute on Aging-Alzheimer's Association workgroups on diagnostic guidelines for Alzheimer's disease. Alzheimers Dement 2011, 7(3):257-262.

10. Sperling RA, Aisen PS, Beckett LA, Bennett DA, Craft S, Fagan AM, Iwatsubo T, Jack CR Jr, Kaye J, Montine TJ, et al: Toward defining the preclinical stages of Alzheimer's disease: Recommendations from the National Institute on Aging-Alzheimer's Association workgroups on diagnostic guidelines for Alzheimer's disease. Alzheimers Dement 2011, 7(3):280-292.

11. Van den Bruel A, Cleemput I, Aertgeerts B, Ramaekers D, Buntinx F: The evaluation of diagnostic tests: evidence on technical and diagnostic accuracy, impact on patient outcome and cost-effectiveness is needed. J Clin Epidemiol 2007, 60(11):1116-1122.

12. Knottnerus JA, Buntinx F: The evidence base of clinical diagnosis: theory and methods of diagnostic research. 2nd edition. Oxford Hoboken, NJ: WileyBlackwell Pub./BMJ Books; 2009.

13. Schaafsma JD, van der Graaf $Y$, Rinkel GJ, Buskens E: Decision analysis to complete diagnostic research by closing the gap between test characteristics and cost-effectiveness. J Clin Epidemiol 2009, 62(12):1248-1252.

14. Cushman LA, Scherer MJ: Psychological assessment in medical rehabilitation. 1st edition. Washington, DC: American Psychological Association; 1995

15. Morris JC: The Clinical Dementia Rating (CDR): current version and scoring rules. Neurology 1993, 43(11):2412-2414.

16. Hughes CP, Berg L, Danziger WL, Coben LA, Martin RL: A new clinical scale for the staging of dementia. Br J Psychiatry 1982, 140:566-572. 
17. Almeida OP, Almeida SA: Short versions of the geriatric depression scale: a study of their validity for the diagnosis of a major depressive episode according to ICD-10 and DSM-IV. Int J Geriatr Psychiatry 1999, 14(10):858-865.

18. Cummings JL: The neuropsychiatric inventory: Assessing psychopathology in dementia patients. Neurology 1997, 48(5):S10-S16.

19. Gelinas I, Gauthier L, McIntyre M, Gauthier S: Development of a functional measure for persons with Alzheimer's disease: the disability assessment for dementia. Am J Occup Ther 1999, 53(5):471-481.

20. Vernooij-Dassen MJ, Felling AJ, Brummelkamp E, Dauzenberg MG, van den Bos GA, Grol R: Assessment of caregiver's competence in dealing with the burden of caregiving for a dementia patient: a Short Sense of Competence Questionnaire (SSCQ) suitable for clinical practice. J Am Geriatr Soc 1999, 47(2):256-257.

21. Vernooij-Dassen MJ: Dementia and Homecare: Determinants of the sense of Competence of Primary Caregivers and the effect of Professionally Guided Caregiver Support. Lisse: Swets \& Zeitlinger; 1993.

22. Brand $\mathrm{N}$, Jolles J: Learning and retrieval rate of words presented auditorily and visually. J Gen Psychol 1985, 112(2):201-210.

23. Rey A: L'examen clinique en psychologie. Oxford England: Presses Universitaries De France; 1958.

24. Lindeboom J, Schmand B, Tulner L, Walstra G, Jonker C: Visual association test to detect early dementia of the Alzheimer type. J Neurol Neurosurg Psychiatry 2002, 73(2):126-133.

25. Wechsler D: Wechsler Memory Scale - 3rd edition: Administration and Scoring Manual. San Antonio: The Psychological Corporation; 1997.

26. Natu MV, Agarwal AK: Digit Letter Substitution Test (DLST) as an alternative to Digit Symbol Substitution Test (DSST). Human Psychopharmacology: Clinical and Experimental 1995, 10(4):339-343.

27. Stroop JR: Studies of interference in serial verbal reactions. J Exp Psychol 1935, 18(6):643-662.

28. Reitan RM: Validity of the Trail Making Test as an indicator of organic brain damage. Percept Mot Skills 1958, 8:271-276.

29. Reitan RM: Trail Making Test: Manual for administration, scoring, and interpretation. Bloomington: Indiana University; 1956.

30. Brooks R: EuroQol: The current state of play. Health Policy 1996, 37(1):53-72.

31. Lamers LM, Stalmeier PF, McDonnell J, Krabbe PF, van Busschbach JJ: Measuring the quality of life in economic evaluations: the Dutch EQ-5D tariff. Ned Tijdschr Geneeskd 2005, 149(28):1574-1578.

32. Lamers LM, McDonnell J, Stalmeier PF, Krabbe PF, Busschbach JJ: The Dutch tariff: results and arguments for an effective design for national EQ-5D valuation studies. Health Econ 2006, 15(10):1121-1132.

33. Jonsson $L$, Andreasen $N$, Kilander $L$, Soininen $H$, Waldemar $G$, Nygaard $H$, Winblad B, Jonhagen ME, Hallikainen M, Wimo A: Patient- and proxyreported utility in Alzheimer disease using the EuroQoL. Alzheimer Dis Assoc Disord 2006, 20(1):49-55.

34. Wolfs CA, Dirksen CD, Kessels A, Willems DC, Verhey FR, Severens LL: Performance of the EQ-5D and the EQ-5D $+C$ in elderly patients with cognitive impairments. Health Qual Life Outcomes 2007, 5:33.

35. Dolan P: Modeling valuations for EuroQol health states. Med Care 1997, 35(11):1095-1108.

36. Brooks RG, Rabin R, De Charro F: The measurement and valuation of health status using EQ-5D: a European perspective: evidence from the EuroQol BIOMED Research Programme. Dordrchet; Boston: Kluwer Academic Pub; 2003.

37. Logsdon RG, Gibbons LE, McCurry SM, Teri L: Assessing quality of life in older adults with cognitive impairment. Psychosom Med 2002, 64(3):510-519.

38. Thorgrimsen L, Selwood A, Spector A, Royan L, de Madariaga Lopez M, Woods RT, Orrell M: Whose quality of life is it anyway? The validity and reliability of the Quality of Life-Alzheimer's Disease (QoL-AD) scale [comment]. Alzheimer Dis Assoc Disord 2003, 17(4):201-208.

39. Spector A, Thorgrimsen L, Woods B, Royan L, Davies S, Butterworth M, Orrell M: Efficacy of an evidence-based cognitive stimulation therapy programme for people with dementia: randomised controlled trial [comment]. Br J Psychiatry 2003, 183:248-254.

40. Brouwer WB, van Exel NJ, van Gorp B, Redekop WK: The CarerQol instrument: a new instrument to measure care-related quality of life of informal caregivers for use in economic evaluations. Qual Life Res 2006, 15(6):1005-1021.
41. Wimo A, Winblad B: Resource utilization in dementia. Brain \& Aging 2003, 3:48-60.

42. Koopmanschap MA, Meerding WJ, Evers S, Severens J, Burdorf A, Brouwer W: Handleiding voor het gebruik van PRODISQ versie 2.1 (PROductivity and DISease Questionnaire). Een modulaire vragenlijst over de relatie tussen ziekte en productiviteitskosten. Toepasbaar bij economische evaluaties van gezondheidszorgprogramma's voor patiënten en werknemers. Rotterdam/ Maastricht. 2004.

43. van Roijen L, Essink-Bot ML, Koopmanschap MA, Bonsel G, Rutten FF: Labor and health status in economic evaluation of health care. The Health and Labor Questionnaire. Int J Technol Assess Health Care 1996, 12(3):405-415.

44. Jack CR Jr, Knopman DS, Jagust WJ, Shaw LM, Aisen PS, Weiner MW, Petersen RC, Trojanowski JQ: Hypothetical model of dynamic biomarkers of the Alzheimer's pathological cascade. Lancet Neurol 2010, 9(1):119-128.

45. Gabel MJ, Foster NL, Heidebrink JL, Higdon R, Aizenstein HJ, Arnold SE, Barbas NR, Boeve BF, Burke JR, Clark CM, et al: Validation of consensus panel diagnosis in dementia. Arch Neurol 2010, 67(12):1506-1512.

46. Brook RH, Chassin MR, Fink A, Solomon DH, Kosecoff J, Park RE: A method for the detailed assessment of the appropriateness of medical technologies. Int J Technol Assess Health Care 1986, 2(1):53-63.

47. Mauskopf JA, Paul JE, Grant DM, Stergachis A: The role of costconsequence analysis in healthcare decision-making. Pharmacoeconomics 1998, 13(3):277-288.

48. Briggs AH, Claxton K, Sculpher MJ: Decision modelling for health economic evaluation. Oxford: Oxford University Press; 2006.

49. Visser PJ, Scheltens $\mathrm{P}$, Verhey FR: Do $\mathrm{MCl}$ criteria in drug trials accurately identify subjects with predementia Alzheimer's disease?J Neurol Neurosurg. Psychiatry 2005, 76(10):1348-1354.

50. Claxton K: The irrelevance of inference: a decision-making approach to the stochastic evaluation of health care technologies. J Health Econ 1999, 18(3):341-364.

51. Mueller SG, Weiner MW, Thal L, Petersen RC, Jack C, Jagust W, Trojanowski $J Q$, Toga AW, Beckett L: The Alzheimer's disease neuroimaging initiative. Neuroimaging Clin N Am 2005, 15(4):869-877. xi-xii.

52. Visser PJ, Verhey FR, Boada M, Bullock R, De Deyn PP, Frisoni GB, Frolich L, Hampel H, Jolles J, Jones R, Minthon L, Nobili F, Olde Rikkert M, Ousset PJ, Rigaud AS, Scheltens P, Soininen H, Spiru L, Touchon J, Tsolaki M, Vellas B, Wahlund LO, Wilcock G, Winblad B: Development of screening guidelines and clinical criteria for predementia Alzheimer's disease. The DESCRIPA Study. Neuroepidemiology 2008, 30(4):254-265.

53. Visser PJ, Kester A, Jolles J, Verhey F: Ten-year risk of dementia in subjects with mild cognitive impairment. Neurology 2006, 67(7):1201-1207.

doi:10.1186/1471-2377-12-72

Cite this article as: Handels et al:: Diagnostic and economic evaluation of new biomarkers for Alzheimer's disease: the research protocol of a prospective cohort study. BMC Neurology 2012 12:72.

\section{Submit your next manuscript to BioMed Central and take full advantage of:}

- Convenient online submission

- Thorough peer review

- No space constraints or color figure charges

- Immediate publication on acceptance

- Inclusion in PubMed, CAS, Scopus and Google Scholar

- Research which is freely available for redistribution 